CAVALCANTE, M.M.A.S. et al. Strongyloidose em ruminantes. PUBVET, Londrina, V. 8, N. 21, Ed. 270, Art. 1800, Novembro, 2014.

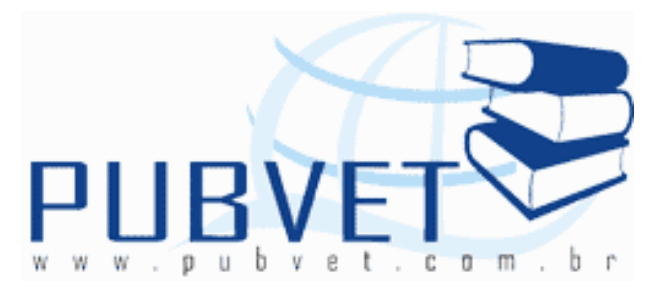

PUBVET, Publicações em Medicina Veterinária e Zootecnia.

\title{
Strongyloidose em ruminantes
}

Maria Michele Araújo de Sousa Cavalcante ${ }^{1}$, Andrezza Braga Soares da Silva ${ }^{1}$, Jéssica Cristianne Mazer Bernardi ${ }^{1}$, Bruno Carneiro Pinheiro ${ }^{1}$, Cleômenes Oliveira Melo ${ }^{1}$, Francisco de Assis Leite Souza ${ }^{2}$, Airton Mendes Conde Junior ${ }^{3}$

${ }^{1}$ Acadêmica de Medicina Veterinária

2 Professor MSc. Substituto

${ }^{3}$ Professor Doutor Adjunto

\section{Resumo}

Os parasitismos gastrointestinais são de grande importância na criação zootécnica de ruminantes domésticos. Dentre estas, se destacam nematóides do gênero Strongyloides, que proporciona uma das mais importantes afecções nematóides gastrintestinais de ruminantes de produção,parasitas de grande prevalência no Brasil, onde encontra condições climáticas adequadas para seu desenvolvimento nas pastagens. Infecções clínicas e subclínicas levam à prejuízos através de perda de produtividade e até mesmo morte súbita de animais acometidos. Portanto, buscando minimizar os impactos provocados por estes parasitas em rebanhos de produção, foram realizadas pesquisas em torno dos aspectos etiológicos, patológicos, epidemiológicos desses parasitas com o intuito de promover um diagnóstico preciso e um tratamento adequado para ruminantes que estivessem infectados com S.papillosus. O conhecimento do ciclo de vida complexo, biologia e sinais clínicos em infecções por 
CAVAlCANTE, M.M.A.S. et al. Strongyloidose em ruminantes. PUBVET, Londrina, V. 8, N. 21, Ed. 270, Art. 1800, Novembro, 2014.

Strongiloides é de grande importância nesta batalha constante pelo controle desta enfermidade, através de técnicas de manejo, diagnóstico e tratamento modernas.

Palavras-chave: Doenças parasitárias. Nematódeos. Ruminantes. Estrongiloidose. Antiparasitários.

\section{Strongyloidose in ruminants}

\section{Abstract}

Gastrointestinal parasitism is of great importance in livestock breeding of domestic ruminants. Among these, we highlight nematodes of the genus Strongyloides, which provides one of the most important diseases of ruminant gastrointestinal nematode parasites of producing, high prevalence in Brazil, where it finds suitable climatic conditions for its development in the pastures. Clinical and subclinical infections lead to financial losses through decrease of productivity and even sudden death. Therefore, trying to minimize the impacts caused by these parasites in livestock production, surveys were conducted around the etiological, pathological, epidemiological aspects of these parasites in order to provide an accurate diagnosis and appropriate treatment for ruminants were infected with S.papillosus. Knowledge of it's complex life cycle and clinical signs of Strongyloidosis is key to control this disease, through advanced techniques of management, diagnosis and treatment.

Keywords: Parasites. Nematodes.Ruminants.Strongyloidosis. Antiparasites.

\section{INTRODUÇÃO}

A criação de ruminantes tem exercido um papel fundamental na pecuária brasileira, visto que sua produtividade está diretamente ligada ao desempenho integrado dos manejosnutricional, sanitário, reprodutivo e à qualidade genética dos animais (VIANA et al., 2009).Esta atividade constitui uma das formas básicas de subsistência das populações de regiões semiáridas, no entanto, a prevalência de verminoses gastrintestinais está entre um dos 
CAVALCANTE, M.M.A.S. et al. Strongyloidose em ruminantes. PUBVET, Londrina, V. 8, N. 21, Ed. 270, Art. 1800, Novembro, 2014.

fatores que contribuem para aumentar a mortalidade e baixar o rendimento dos rebanhos bovinos, caprinos e ovinos no território brasileiro (ARAUJO et al., 2006; PEREIRA et al., 2008; FONSECA et al., 2012).

Dentre as verminoses gastrintestinais que acometem ruminantes, os parasitas da classeNematoda mostraram ser de tamanha importância na incidência de casos clínicos em propriedades. Estes, compreendem parasitas de formato cilíndrico com as extremidades (cabeça e cauda) normalmente pontiagudas, alimentando-se de líquido das mucosas, produtos da digestão e fragmentos celulares do hospedeiro (PEDRO, 2011). Nesta classe está inserida a ordem Rhabditida, a qual abriga a superfamília Rhabditoidea da família Strongyloididae, cuja nomenclatura provem do latim 'Strongy' que significa redondo (MONTEIRO, 2007). Porém, a característica marcante das espécies de parasitas desta família éa presença de um esôfago desenvolvidoem formato rabditiforme(ANDERSON, 2000).

Esses vermes intestinais podem abrigar o organismo de diversas espécies animais (SANTOS, 2009; PEDRO, 2011). Assim, cada espécie dentro do gênero Strongyloidesapresenta uma relação exclusiva com determinados hospedeiros, sendo os principais, o S.stercoralisde humanos e cães; oS.papillosusde ruminantes; S. ransomide suínos; S. westeri de equinos e asininos; o S. fuellebornide primatas africanos e asiáticos e de humanos; $S$. cebus de primatas americanos; e S.rattie S.venezuelensisde ratos (MONTEIRO, 2007; BOWMAN, 2010).

Atualmente, a Estrongiloidose é considerada uma das mais importantes afecções nematóides gastrintestinais de ruminantes de produção (ANDRADE, 2010). No Brasil, esta situação é favorável à ocorrência dessas parasitoses, devido às condições climáticas que permitem um bom nível de desenvolvimentodos ovos e de eclosão das larvas que infestarão pastagens (ANDERSON, 2000; BRAGA et al., 2001; VIANA et al., 2009; ANDRADE, 2010).

Uma vez no organismo de ruminantes, a larva infectante de S.papillosusinicia o seu ciclo parasitário e a medida que penetra nos tecidos do animal provoca uma série de sintomas, podendo levar o mesmo à morte 
CAVALCANTE, M.M.A.S. et al. Strongyloidose em ruminantes. PUBVET, Londrina, V. 8, N. 21, Ed. 270, Art. 1800, Novembro, 2014.

súbita, quadro característico da Estrongiloidose (ANDRADE, 2010; ADIZA, 2010). Portanto, buscando minimizar os impactos provocados por estes parasitas em rebanhos de produção, foram realizadas pesquisas em torno dos aspectos etiológicos, patológicos, epidemiológicos desses parasitas com o intuito de promover um diagnóstico preciso e um tratamento adequado para ruminantes que estivessem infectados com S.papillosus (DANILO, 2004; PEDRO, 2006; STREIT, 2007; ANDRADE, 2010; VALERIA, 2011).

\section{REVISÃO DE LITERATURA}

\section{Agente etiológico}

S.papillosusé um parasita gastrintestinal de ruminantes pertencente à ordem Rhabditida, à família Strongyloididae e ao gênero Strongyloides (MONTEIRO, 2007; ANDRADE, 2010; PEDRO, 2011). O gênero Strongyloidesé o único entre os parasitas de animais domésticos que possui gerações parasitárias e de vida livre alternadas (BOWMAN, 2010).

No geral, a espécie apresenta tamanho pequeno (fêmeas parasitas inferiores a $1 \mathrm{~cm}$ ), com ovos de 45 a $65 \mu \mathrm{m}$ de comprimento por $25 \mu \mathrm{m}$ de largura (MONTEIRO, 2007). O parasita pode se apresentar na forma de estádios, no qual o ovo compreende a primeira forma de eliminação pelas fezes do hospedeiro, o que diferencia das outras espécies do gênero Strongyloides. O período de larva compreende uma série de estádios no qual o parasita se desenvolve a medida que encontra condições apropriadas (ARAUJO, 2006; VIANA, 2009; BARBIERE, 2010).

Os ovos apresentam forma elipsoidal, extremidade polares simétricas e uma casca delgada, com as superfícies internas e externas lisas, composta por uma camada uniforme. (VIEIRA, 2006; PINTO, 2008). Os ovos de nematóides do gênero Strongyloidespossuem tamanhos que variam entre $40 \mu \mathrm{m}$ e $70 \mu \mathrm{m}$ de comprimento e a largura média com cerca da metade do comprimento, e na oviposição já contém a larva do primeiro estádio (VIEIRA, 2006). 
CAVALCANTE, M.M.A.S. et al. Strongyloidose em ruminantes. PUBVET, Londrina, V. 8, N. 21, Ed. 270, Art. 1800, Novembro, 2014.

As larvas do Strongyloides papillosus apresentam cinco estádios diferentes, sendo que apenas o terceiro compreende a forma infectante do parasita, o dois primeiros pertencem ao ciclo de vida livre (no ambiente) e os dois últimos estádios podem pertencer ao ciclo de vida parasitária (no hospedeiro) ou ao ciclo de vida livre (SANTOS, 2009; ANDRADE, 2010). No geral, as larvas possuem esôfago desenvolvido, intestino, cauda, órgãos genitais e ânus (BOWMAN, 2010).

Morfologicamente, as larvas do primeiro estádio (L1), possuem comprimento total entre 270 e $350 \mu \mathrm{m}$, esôfago do tipo rhabditiforme, com corpo, istmo e bulbo distintos e evidentes com comprimento total entre 75 e

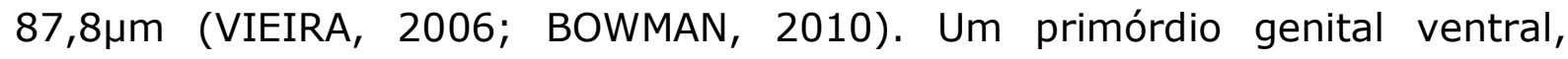
proeminentee alongado possuindo entre cinco e nove células e um lobo cefálico ventral e outro dorsal, separados pela abertura bucal, que possui formato oval (VIEIRA, 2006; BOWMAN, 2010).

As larvas L1 passam por processo de muda e logo se transformam em larvas de segundo estádio (L2), morfologicamente semelhantes às anteriores, porém com um esôfago mais alongado (entre 90 e $107 \mu \mathrm{m}$ de comprimento), com as divisões do corpo menos pronunciadas, ocorre um aumento de todo o corpo da larva, e a redução do tamanho do primórdio genital (VIEIRA et al., 2006). Dependendo das condições ambientais, a L2 passa pelo processo de muda transformando-se em larvas de terceiro estádio ou L3 (BOWMAN, 2010).

As larvas L3 ou infectantes (por serem as únicas capazes de penetrar no hospedeiro) apresentam comprimento total entre 460 e $662,5 \mu \mathrm{m}$, extremidade anterior arredondada e posterior afilada, esôfago em formato filariforme preenchendo cerca de $40 \%$ do comprimento total do corpo do parasita (VIEIRA et al., 2006; SANTOS, 2009). A larva L3 ainda pode sofrer muda transformado-se em L4 e L5, formas parasitas de vida livre ou, dependendo da situação, de vida parasitária desenvolvendo a fêmea partenogenética que irá produzir os ovos para que serão eliminados nas fezes (VIEIRA, et al., 2006). 
CAVALCANTE, M.M.A.S. et al. Strongyloidose em ruminantes. PUBVET, Londrina, V. 8, N. 21, Ed. 270, Art. 1800, Novembro, 2014.

A fêmea partenogenética possui um comprimento total de $3561 \mu \mathrm{m}$, esôfago preenchendo apenas $21,2 \%$ do comprimento total do corpo sendo em sua maioria ocupado pela vulva, $1251 \mu \mathrm{m}$ onde abriga os ovos (SANTOS et al., 2009).Após a produção dos ovos, estes serão eliminados junto com as fezes e a eliminação dos estádios de Strongyloide spapillosusse caracteriza pela presença de ovos larvados nas fezes recém eliminadas (VIEIRA et al., 2006).

Com isso, as características físicas e comportamentais dos parasitas S.papillosus definem a prevalência da infecção em ruminantes, podendo ser eliminando do organismo uma vez que o hospedeiro seja submetido à substâncias que sejam capazes de neutralizar as características patológicas do agente (ANDRADE, 2010).

\section{Aspectos epidemiológicos}

O parasitismo gastrintestinal é um importante fator econômico responsável pela baixa produção, sendo considerado um sério problema de saúde na criação de pequenos ruminantes, promovendo uma série de sintomas, a depender do grau de parasitismo e hábitos alimentares dos helmintos envolvidos (BUZZULINI et al., 2007; SILVA et al., 2008). Para um controle efetivo dos parasitos gastrintestinais, é necessário um conhecimento dos fatores epidemiológicos relacionados ao ambiente e aos parasitos e de fatores fisiológicos intrínsecos ao hospedeiro, que acabam determinando uma interação entre eles (GENNARI et al., 2002 apud PINTO et. al.,2008).

O bolo fecal pode ser considerado uma incubadora, no qual as larvas se desenvolvem até as larvas infectantes. O bolo fecal constitui-se ainda um abrigo com uma cobertura interior impermeável endurecida pelo sol. Considerando que o teor de oxigênio é essencial, os ovos da superficie evoluem primeiro, e em seguida, os ovos localizados nas camadas mais baixas (FONSECA, 2006).

O conhecimento da época do ano em que as larvas ocorrem em maior ou menor número nas pastagens constitui um dado essencial para o entendimento da dinâmica populacional dos parasitos em determinada região e 
CAVALCANTE, M.M.A.S. et al. Strongyloidose em ruminantes. PUBVET, Londrina, V. 8, N. 21, Ed. 270, Art. 1800, Novembro, 2014.

no estabelecimento de medidas de controle estratégico (PEREIRA et al., 2008). As estrongiloidoses são típicas de países tropicais e subtropicais. Nostemperados, observa-se nas regiões mais úmidas, cálidas e sombrias (ANDRADE, 2010).

O número de helmintos presentes no interior dos hospedeiros é maior no período seco do que no chuvoso observando, portanto uma relação inversa entre o número de larvas infectantes nas pastagens e o número de larvas adultas nos animais (PEREIRA et al., 2008). De acordo com Andrade (2010), os animais jovens são mais susceptíveis que os adultos, além disso, as larvas infectantes carecem de bainha e são muito sensíveis a condições climáticas adversas. O calor e a umidade favorecem o desenvolvimento e permitem a acumulação de grande número de larvas infectantes. A dessecação destrói as larvas em 5-10 minutos, assim como fortes variações de temperatura (ARGUELLO; CORDERO DEL CAMPILLO, 2002 apud ANDRADE, 2010).

Outro fator de risco para o estabelecimento da doença é a curta duração de desenvolvimento dos parasitas, no qual os animais jovens muito rapidamente se convertem em eliminadores, contribuindo para aumentar a intensidade da infecção (GUTIÉRREZ et al.,2008).

\section{Susceptibilidade}

Os animais mais susceptíveis as verminoses gastrointestinais são os animais jovens, por não possuírem um sistema de defesa eficiente, capaz de responder aos danos causados pelos parasitos. Com o passar do tempo, os animais vão adquirindo imunidade relativa após sucessivas infecções e esses animais podem apresentar um quadro subclínico da doença, o que faz com que a contaminação das pastagens perdure devido à eliminação de ovos pelas fezes dos animais infectados (LIMA, GUIMARÃES, 1992; MELLO, COUTINHO, 1994).

SANTA ROSA et. al. (1986) afirmam que em algumas situações fisiológicas como prenhes, lactação e subnutrição, pode ocorrer infecção grave em todos os animais do rebanho, independente da faixa etária, devido a 
CAVALCANTE, M.M.A.S. et al. Strongyloidose em ruminantes. PUBVET, Londrina, V. 8, N. 21, Ed. 270, Art. 1800, Novembro, 2014.

quebra no equilíbrio/parasito. Outra situação onde esse desiquilíbrio pode ocorrer é quando há ingestãoexacerbada de ovos infectantes.

No período do periparto, principalmente das ovelhas, já é conhecido e relatado um fenômeno conhecido como "springrise" ou quebra da imunidade, levando a um aumento no número de ovos por grama de fezes (OPG) e a um aumento da carga parasitária(PINTO, 2008). Esse fenômeno permite uma maior fecundidade dos adultos pré-existentes e um maior estabelecimento de novas larvas, e ocorre principalmente no final do parto e no início da lactação, diminuindo após o desmame (COSTA, 1983; GENNARI et.al. 2002).

Segundo Amarante et. al. (1992), uma consequência importante da eliminação de ovos no período do periparto é o aumento da contaminação das pastagens pelos estágios de vida livre dos estrongiloides gastrointestinais. Em consequência disso, o parasitismo do rebanho pode atingir níveis prejudiciais (COSTA, 1983). Alguns autores afirmam que esse aumento do OPG no período de periparto seja uma adaptação evolutiva dos parasitas, onde eles teriam uma maior oportunidade de transmissão de um hospedeiro para outro.

Alguns trabalhos vêm sendo realizados para avaliar a susceptibilidade das diferentes espécies de animais a parasitos gastrointestinais. Em um estudo realizado por COSTA et.al. (2011) no semiárido do Nordeste do Brasil, foi constatado que os caprinos são mais infectados do que os ovinos, em condições de pastoreio, em pastagens. Isso se explica pela menor habilidade desses animais de desenvolverem uma resposta imune (HOSTE et. al., 2007). Já em condições de consumo de folhas e ramas de árvores, as ovelhas são frequentemente mais infectadas do que as cabras. Esse fato é explicado pela vantagem das cabras em explorar brotos em posição bipedal, evitando contato excessivo com os estágios infectantes, que se encontram no solo.

\section{Ciclo biológico}

Diferentemente da maioria dos nematódeos, o ciclo de vida de qualquer espécie de Strongyloides é dividido em 2 modos: o direto ou homogônico e o indireto ou heterogônico. Os parasitas adultos no hospedeiro definitivo são 
CAVALCANTE, M.M.A.S. et al. Strongyloidose em ruminantes. PUBVET, Londrina, V. 8, N. 21, Ed. 270, Art. 1800, Novembro, 2014.

exclusivamente fêmeas se reproduzindo partenogeneticamente (KHUMPOOL, 2012). Essas fêmeas são triplóides (3n) e elas produzem ovos que passam para as fezes. No $1^{0}$ estágio, as larvas eclodem dos ovos e podem se desenvolver para o $3^{\circ}$ estágio larval infectante (ciclo homogônico) ou para machos e fêmeas de vida livre (ciclo heterogônico). O macho de vida livre é haplóide (1n), enquanto a fêmea de vida livre é diplóide (2n). (KHUMPOOL, 2012).

Os machos, de vida livre, cruzam com as fêmeas e estas botam ovos não embrionados que desenvolverão larvas exclusivamente fêmeas triplóides infectantes.As larvas L1 eclodem dos ovos embrionados 6 horas após esses ovos serem depositados e eliminados nas fezes, a $27^{\circ} \mathrm{C}$. A primeira muda tem lugar 7-10 horas depois da eclosão, onde a larva L1 passará a ser a larva L2. Em seguida, no ciclo direto, muda para L3 infectante e filariforme depois de 26-28 horas. Já a segunda muda no ciclo indireto, a L3 rabditiforme tem lugar em 14-16 horas. A diferenciação sexual começa nesse momento. A L4 rabditiforme origina-se em 21 horas e os adultos rabditiformes aparecem em 28 horas. (ANDRADE, 2010).

Os ovos não embrionados, produzidos por machos e fêmeas de vida livre, eclodem em 6-10 horas e as L1 rabditiformes são exatamente iguais às que eclodem de ovos de fêmeas parasitas. (ANDRADE, 2010).Pode ocorrer também a auto-infecção que possui 2 modos: a externa, onde ocorre a transformação de larvas rabditóides em filarióides infectantes na pele da região anal ou perianal; e a interna, onde casos de baixa imunidade podem propiciar a evolução do parasita no intestino delgado ou grosso e penetração direta da mucosa por L2 (KHUMPOOL, 2012).

\section{Patogenia}

A infecção pelo parasita inicia com a penetração da larva L3 no hospedeiro, e esta pode ocorrer de três modo, ou seja, existem três rotas de infecção por S. papillosus: a via oral, percutânea e transmamária. Alguns autores insistem que a principal via é a transmamária devido a maioria dos 
CAVALCANTE, M.M.A.S. et al. Strongyloidose em ruminantes. PUBVET, Londrina, V. 8, N. 21, Ed. 270, Art. 1800, Novembro, 2014.

hospedeiro acometidos, que são animais jovens, porém a via percutânea ainda é tratada como a mais relevante devido a gama de hospedeiros do gênero que não incluem apenas ruminantes. O verme penetra na pele (regiões que mais ficam em contato com o solo, espaço interdigitais, abdômen, úbere e axilas) através da degradação de macromoléculas cutâneas usando enzimas proteolíticas que os mesmos produzem (protease aspártica 2 e lisozimas), alcançando a circulação venosa e linfática (ANDRADE, 2010; KHUMPOOL, 2012).

Ao chegarem na circulação venosa têm decorrido aproximadamente cinco minutos, logo, estes parasitas alcançam o coração, no qual podem ser encontrados em dados de necropsia, e neste órgão podem provocar problemas circulatórios, como anemia, ruptura de capilares, processos inflamatórios, abrir portas para a entrada de outros agentes, entre outros. Do coração, os para sitas chegam no pulmão através de capilares alveolares e atravessam a membrana alveolar já como larvas L4, atingindo a árvores traqueobrônquica. Para o sistema respiratório, decorreram em media 24 horas, e podem ser encontradas em outras partes do corpo, como diafragma, cavidade abdominal, sobretudo quando penetram de feridas (ANDRADE, 2010; KHUMPOOL, 2012).

$\mathrm{Na}$ faringe estas larvas são expelidas ou deglutidas atingindo o sistema gastrintestinal, alojando -se no intestino delgado, 48 horas depois, como larvas partenogenéticas ou L5. Estas, através de partenogênese produzem ovos embrionados, que irão passar para ovos larvados sendo eliminados junto com as fezes. Até que os ovos do parasita apareçam nas fezes do hospedeiro, leva cerca de 6 a 7 dias. A partir de então, ele inicia o seu ciclo de vida livre (ANDRADE, 2010; KHUMPOOL, 2012).

$\mathrm{Se}$ as larvas forem ingeridas passivamente, desenvolvem-se diretamente no intestino delgado sem migração. Também pode existir infecção transmamáriapor ingestão de leite materno ou colostro, com diminuição do período de pré-patência. Acredita-se que as larvas atingem as glândulas mamárias através da circulação sanguínea dos grandes vasos que irrigam a as mesmas. (ARGUELLO; CORDERO DEL CAMPILLO, 2002 apud ANDRADE, 2010). 
CAVALCANTE, M.M.A.S. et al. Strongyloidose em ruminantes. PUBVET, Londrina, V. 8, N. 21, Ed. 270, Art. 1800, Novembro, 2014.

As infeç̧ões geralmente são ligeiras, assintomáticas e pouco patogênicas. Apenas infecções massivas podem causar sintomatologia clínica. A patogenia da estrongiloidose depende dos transtornos digestivos provocados pelos parasitas adultos no duodeno de no jejuno, o que produz alterações a digestão e absorção levando a atrasos no crescimento e perda de peso. Os adultos exercem também uma ação tóxica devido a produtos de secreção e excreção, que lesionam a mucosa e favorecem a penetração de bactérias, como Salmonellaou colibacilos. Ao perfurarem a pele as larvas exercem uma ação tóxica devido às enzimas que secretam, podem obstruir os capilares, alimentam-se de exsudato capilar e ainda podem vincular bactérias aderidas a elas. As lesões pulmonares provocadas pelas larvas migratórias podem exacerbar infecções víricas e bacterianas que estavam latentes originando pneumonias (ARGUELLO; CORDERO DEL CAMPILLO, 2002 apud ANDRADE, 2010; PEREZ E MARTIN, 2008).

\section{Sinais Clínicos}

Os sinais cínicos não são frequentes em infecções com S. papillosus, entretanto alto número de larvas infectantes por infecção percutânea pode causar súbita morte cardíaca. (KHUMPOOL, 2012).

Segundo Braga (2001), em bezerros os sintomas encontrados foram apetite reduzido, abdômen retraído, diarreia intermitente, prostração e pelos sem brilho. A perda de peso esteve presente em $50 \%$ dos animais pesquisados, $30 \%$ sustentaram o peso inicial e os $20 \%$ restantes o ganho de peso foi em torno da metade do ganho de peso observado no grupo controle.A morbidade ou mortalidade foi decorrente da debilidade orgânica geral.

O sintomas cutâneos (reação eritematosa) existem quando a infecção é massiva. A dermatite difusa na zona do costado e abdômen, inflamação, edemas e urticária são originadas das contínuas exposições ao agente. Os sintomas pulmonares caracterizam-se por taquipneia, tosse, estertores e em alguns casos quando favorecida por infecções bacterianas secundárias, surgem 
CAVALCANTE, M.M.A.S. et al. Strongyloidose em ruminantes. PUBVET, Londrina, V. 8, N. 21, Ed. 270, Art. 1800, Novembro, 2014.

as pneumonias (ARGUELLO; CORDERO DEL CAMPILLO, 2002 apud ANDRADE, 2010).

Outros sinais apresentados são retardo no crescimento, baixas na produção leiteira, anorexia,enoftalmia (afundamento do globo ocular na órbita), desidratação, bruxismo e formação de espuma na boca. Ocasionalmente o hospedeiro pode apresentar ligeiramente anemia e sinais nervosos tais como ataxia, postura ampla baseada, estupor e nistagmo(ANDRADE, 2010).

\section{Diagnóstico}

Basear-se apenas nos sinais clínicos dos animais, não é o suficiente para obter um diagnóstico ágil e exato de Estrongiloidose em ruminantes, para isso, o veterinário necessita complementar o diagnóstico clínico com exame de fezes (UENO et al., 1998).

A infecção pode ser confirmada pela demonstração de ovos no exame fecal (OPG), mas deve-se levar em consideração os seguintes aspectos: uma contagem de OPG nem sempre constitui indicação precisa do número de vermes adultos presentes e a identificação específica não é prática. As contagens de OPG podem ficar negativas ou enganosamente baixas na presença de grande número de vermes imaturos. Mesmo quando se encontram presentes muitos parasitas adultos, a contagem pode ficar baixa se a eliminação de ovos tiver sido suprimida por uma reação imune ou um tratamento anti-helmíntico anterior, aliás, as variações na capacidade de produção de vermes também podem distorcer o quadro verdadeiro (AIELLO, 2001 apud ANDRADE et al., 2010).

Associado aos sinais clínicos e ao exame de fezes confiável, também pode ser realizada necropsia de alguns doentes, visando a obtenção de vermes adultos (AIELLO, 2001 apud ANDRADE, 2010). Para visualização das larvas, pode ser realizado a coprocultura de fezes coletadas do reto para evitar contaminação com nematóides de vida livre, onde as larvas parasitas adultas, 
CAVALCANTE, M.M.A.S. et al. Strongyloidose em ruminantes. PUBVET, Londrina, V. 8, N. 21, Ed. 270, Art. 1800, Novembro, 2014.

isoladas do intestino, podem ser claramente identificadas pelos seus órgãos genitais femininos e pela relatividade do esôfago longo (KHUMPOOL, 2012).

Hipobiose ou desenvolvimento larval inibido é um artifício usado pelos parasitas para evitar condições climáticas adversas às suas progênies e permanecer sexualmente imaturos até que haja boas condições para seu desenvolvimento. Sua importância epidemiológica se deve ao fato de assegurar a sobrevivência do nematódeo, no hospedeiro, durante períodos adversos. A subseqüente maturação de larvas inibidas aumenta a contaminação do meio ambiente, podendo, às vezes, resultar em doença clínica. O acúmulo de larvas hipobióticas coincide com o início do período seco nas regiões tropicais e subtropicais. Sua volta ao estado larval maturo coincide com o retorno das condições favoráveis no início do período chuvoso, no entanto, não está claro o que dispara o sinal para a volta da maturação dessas larvas (COSTA et al., 2011).

\section{Tratamento}

O tratamento de nematodioses gastrintestinais em ruminantes consiste na utilização de anti-helmínticos, no entanto, o aparecimento de resistência aos princípios ativos despertou o interesse no desenvolvimento de drogas com largo espectro de ação (SILVA et al., 2008). Dentre os compostos disponíveis, existem quatro grupos químicos distintos que são os mais utilizados: os benzimidazóis, as pirimidinas, os imidazotiazóis e o grupo das lactonasmacrocíclicas. A grande diferença entre os grupos químicos está no seu mecanismo de ação diferenciado e nas formas de eliminação parasitária (BORDIN, 2004 apud SILVA et al., 2008).

Atualmente, a ivermectina, na dose de $0,2 \mathrm{mg} / \mathrm{Kgpv}$, parece ser 0 tratamento de escolha para quase todas as espécies de Strongyloides, incuindo a S. papillosusde ruminantes (BOWMAN, 2010). Segundo Arguello \& Cordero del Campillo (2002), o tratamento das afecções provocadas por esta espécie de Strongyoides é realizado com febendazol, na dose de $5 \mathrm{mg} / \mathrm{Kgpv}$, e ainda com moxidectina, na mesma dose da ivermectina. 
CAVALCANTE, M.M.A.S. et al. Strongyloidose em ruminantes. PUBVET, Londrina, V. 8, N. 21, Ed. 270, Art. 1800, Novembro, 2014.

Entretanto, não se deve estimular o uso de anti-helmínticos associados em rebanhos comerciais, justamente para não acelerar a resistência do parasita (SILVA et al., 2008).

\section{Controle e Profilaxia}

O controle de Strongyloidoses em ruminantes é principalmente com base no tratamento do gado com anti-helmínticos; no entanto, esta prática nem sempre é efetiva devido ser cada vez mais frequente os casos de resistência das populações helmínticas (SOUTELLO et al., 2003 apud SANTOS et al; 2009). Assim, uma conduta baseada em um sistema sanitário e manejo zootécnico adequado associado com estudos epidemiológicos, poderiam minimizar o uso desses antiparasitários (SANTOS et al., 2010).

O controle de afecções causadas por Nematóides pode basear-se em medidas alternativas, como manejo de pastos e ainda em um sistema integrado que envolve a associação com o uso de anti-helmínticos (ANDRADE, 2010). A rotação de pastagens pretende eliminar ou reduzir a ingestão de larvas infectantes permitindo que os animais pastem unicamente durante menos de uma semana em uma zona concreta do pasto, de maneira que os ovos eliminados com as fezes não tenham tempo de se desenvolver originando larvas infectantes, e não deixando que os animais voltem até que as larvas estejam extintas (ARGUELLO; CORDERO DEL CAMPILLO, 2002 apud ANDRADE, 2010).

Outras medidas que podem ser implementadas na propriedade para diminuir o uso de produtos químicos e desaparecimento de infecções gastrintestinais incluem: a construção de esterqueiras na propriedade, evitar a superlotação das pastagens; separar os animais por faixa etária; não introduzir no rebanho animais provenientes de outras propriedades antes de serem vermifugados (isto evita a introdução na propriedade de estirpes resistentes), evitar soltar os animais nas primeiras horas do dia e manter os animais no aprisco, no mínimo até 12 horas até a vermifugação visando obter melhores 
CAVALCANTE, M.M.A.S. et al. Strongyloidose em ruminantes. PUBVET, Londrina, V. 8, N. 21, Ed. 270, Art. 1800, Novembro, 2014.

resultados quando da utilização de controle químico (VIEIRA, 2007; ANDRADE, 2010).

O manejo integrado de parasitos é a combinação e a utilização de métodos químicos e não químicos de controle parasitários disponíveis, com a finalidade de minimizar a dependência química e manter níveis aceitáveis de produção sem a eliminação total do agente causal. Como por exemplo, o uso de fungos nematófogos (LARSEN, 1999 apud ANDRADE, 2010; GONÇALVES; ECHEVARRIA, 2004 apud ANDRADE, 2010).

Além disso, a suplementação protéica pode diminuir os efeitos do parasitismo, melhorar a imunidade do hospedeiro e reduzir a carga parasitária (COOP ; KYRIAZAKIS, 2001 apud ANDRADE, 2010).

\section{Impactos Econômicos}

O parasitismo gastrointestinal tem se apresentado como uma importante causa de perdas econômicas na criação de animais ruminantes. Essas perdas poderiam ser ainda maiores, porém, as infecções subclínicas marcaram o real valor do prejuízo gerado. Esses animais são acometidos, na maioria das vezes, por diferentes espécies de parasitas, o que torna o diagnóstico e o tratamento ainda mais difícil para o produtor.

Os efeitos do parasitismo, no desempenho produtivo do rebanho, manifestam-se de várias formas, conforme espécies presentes, a intensidade da infecção e o estado fisiológico e nutricional dos animais. O impacto sobre a produção é refletido no retardo do crescimento, na redução dos parâmetros produtivos e na morte nas categorias mais susceptíveis (VIEIRA, 2003).

Para minimizar ou prevenir a contaminação do rebanho por endoparasitoses, utiliza-se tratamentos comanti-helminticos, o que também gera despesas tanto pela aquisição dos medicamentos, quanto pela mão-debra necessária para a administração correta dessas drogas, a fim de se obter uma eficiência na prevenção das infecções que acometem os animais. Entretanto, vale lembrar que a resistência anti-helmintica é o principal ponto negativo no controle das verminoses de ruminantes. Dessa maneira, o uso de 
CAVAlCANTE, M.M.A.S. et al. Strongyloidose em ruminantes. PUBVET, Londrina, V. 8, N. 21, Ed. 270, Art. 1800, Novembro, 2014.

medicação anti-helmintica só é vantajosa, se no momento indicada, proporcionar um incremento na produção muito superior ao gasto com o tratamento. (PINHEIRO, 1983; VIEIRA, 2003)

Dessa maneira, sabendo-se da importância das verminoses na criação de animais ruminantes, dos entraves da resistência anti-helmintica e dos resíduos químicos que são liberados no ambiente (resíduos de compostos químicos eliminados com as excreções dos animais), que provocam sérios efeitos ao meio ambiente, é de fundamental importância o estudo de métodos alternativos de controle das verminoses, não só para complementar os métodos convencionais mas principalmente para diminuir a contaminação do meio ambiente, diminuir os gastos com drogas e também diminuir o efeito da resistência anti-helmintica(URQUHART, 1996; SOUZA, 2011).

\section{CONCLUSÃO}

Infecções clínicas e subclínicas por Strongyloidescausam grandes prejuízos na criação zootécnica de ruminantes. A tendência à diminuição do uso de antiparasitários torna essencial o conhecimento da biologia, ciclo de vida e desenvolvimento da patogênese deste parasita em ruminantes, assim como o desenvolvimento e disseminação de técnicas de manejo para controle deste agente.

\section{REFERÊNCIAS}

AIELLO, S.E.; MAYS, A. Manual Merk de Veterinaria.8.ed., São Paulo: Roca, 2001. 1861p.

ANASTACIO, P.F.B.; Parasitoses gastrintestinais em ovinos em regime extensivo e intensivo em explorações do ribatejo. - portugal. Lisboa, 2001. p.108. Dissertação (Mestrado integrado em Medicina Veterinária). Faculdade de Medicina Veterinaria. Universidade Tecnica de Lisboa. Lisboa, 2011.

ANDERSON, R.C.; ANDERSON, R.C; Nematodeparasitesofvertebrates: TheirDevelopmentandTransmission. 2.ed. New York: CABI Publishion, 2000. 578p.

ANDRADE, F.B; Transmissão transmamária de larvas de Strongyloidespapillosus(Nematoda: Rhabditidadae) em vacas leiteiras no semi-árido paraibano. Patos, 2010. p.34. Monografia. Universidade Federal de Campina Grande. Patos. 2010. 
ARAUJO, J.V.; FREITAS, B.W.; VIEIRA, T.C.; CAMPOS, A.K.; Avaliação do fungo predador de nematóidesDuddingtoniaflagranssobre larvas infectantes de Haemonchuscontortuse Strongyloidespapillosus de caprinos. Rev. Bras. Parasitol. Vet.,Viçosa, v.15, n.2, p.76-79, 2006.

ARGUELLO, M.R.; CORDERO DEL CAMPILLO, M. Estrongiloidosis. In:CorderodelCampillo, M., Vazquez, F.A., Fernandez, A.R., Acedo, M.C., Rodriguez, S.H., Coar, I.N., Banos, P.D., Romero, H.Q.\& Varela, H.C. Parasitologia Veterinaria: Parasitosisdel aparato digestivo.Madrid: eMcGRAW-HILL Interamericana, 2002. p.234-237.

BARBIERI, F.S.; BRITO, L.G.; FIGUEIRÓ, M.R.; BANDEIRA, P.F.; NASCIMENTO, A.X.; Parasitismo natural por helmintos gastrintestinais em búfalos criados em Presidente Médici, Rondônia, Brasil. Porto Velho, RO: EmbrapaRondônia, 2010.p.18.

BASIR, M.A.; Remove from marked Records The morphology and development of the sheep nematode, Strongyloidespapulosos (Wedl, 1856). CanadianJournalofResearch, v. 28, n. 3, p. $173-196,1950$.

BEZERRA, A.C.A.; Frequencia e Intensidade de infecção por helmintos gastrintestinais em caprinos leiteiros criados em condições semi-extensivas no município de Afonso Bezerra - RN. Mossoró, 2010. p.49. Dissertação (Mestrado em Ciência Animal: Área de concentração em e Sanidade Animal), Universidade Federal Rural do Semiárido. Mossoró, 2010.

BORDIN, E.L. Algumas considerações sobre a resistência de nematodas gastrintestinais de ruminantes aos anti-helmínticos. Revista Brasileira de Parasitologia Veterinária, v.13, n. 1, p. $80-81,2004$

BOWMAN, D.D.;GEORGI, J. R.;Parasitologia Veterinária. 9.ed. Rio de Janeiro: Elsevier Brasil, 2010.p.448.

BRAGA, M.M.; FONSECA, A.H.; BRAGA, D.B.O.; NETO, M.P.; CASTRO, A.L.M.; Alterações clinicas em bezerros desmamadossubmetidos à hiperinfecção experimental por Strongyloidespapillosus(WEDL, 1856) (Nematoda: Rhabdiasoidea). R. Bras. Ci. Vet. v.8, n.3, p.137-140, set./dez., 2001.

BUZZULINI, C.; SOBRINHO, A.G.S.; COSTA, A.J.; SANTOS, T.R.; BORGES, F.A.; SOARES, V.E.; Eficácia anti-helmíntica comparativa da associação albendazole, levamisole e ivermectina à moxidectina em ovinos. Pesq.agropec. bras., Brasília, v.42, n.6, p.891-895, jun. 2007.

COOP, R.L.; KYRIAZAKIS, L.; Influence of host nutricion on the development and consequences of nematode parasitism in ruminants.TrendsParasitol. v.17, n.7, p.325-330, 2001

COSTA, V.M.M.; Doenças Parasitárias em ruminantes no semi-árido e alternativas para o controle das parasitoses gastrintestinais em ovinos e caprinos.Patos, 2009. p.58.Dissertação (Mestrado em Medicina Veterinária). Centro de ciência e Tecnologia Rural, Universidade Federal de Campina Grande. Patos, 2009.

COSTA, V.M.M.; SIMÕES, S.V.D.; RIET-CORREA, F.; Controle das parasitoses gastrintestinais em ovinos e caprinos na região semiárida do Nordeste do Brasil. Pesq. Vet. Bras. v. 31. n.1. p.65-71, jan., 2011. 
ECHEVARRIA, F.; BORBA, M.F.S., PINHEIRO, A.C., WALLER, P.J., HANSEN, J.W. The prevalence of anthelmintic resistance in nematode parasites of sheep in southern Latin America: Brasil. Vet. Parasitol., v.62, p.199-206, 1996.

FONSECA, A. R; DUQUE, N. A; BRITTO, M. S. M. Efeitos das infecçöes natural e experimental por Strongyloides papillosus em bezerros / Natural and experimental infection of Strongyloides papillosus in calves. Arq. bras. med. vet. zootec. v.46. n.2. p.111-119, abr., 1994.

FONSECA, Z.A.A.S.; BEZERRA, A.C.A.; AVELINO, D.B.; VIEIRA, L.S.; AHID, S.M.M.; Parasitismo mútuo por cestóides em caprino jovem: relato de caso. Acta VeterinariaBrasilica, v.6, n.1, p.65-67, 2012.

GENNARI, S.M.; BLASQUES, L.S.; RODRIGUES, A.A.R.; CILENTO, M.C.; SOUZA, S.L.B.; FERREIRA, F.; Determinação da contagem de ovos de nematódeos no período peri-parto em vacas. Braz. J. Vet. Res. Anim. Sci., v.39, n.1, São Paulo, 2002.

GONÇALVES, I. G.; ECHEVARRIA, F. Cobre no controle da verminose gastrintestinal em ovinos. Ciência Rural, Santa Maria, v.34, n.1, p.183-188, 2004.

HUTCHINSON, G.H.; Nematode Parasites of Small Ruminants, Camelids and Cattle Diagnosis with Emphasis on Anthelmintic Efficacy and Resistance Testing.Australiaand New Zealand Standard Diagnostic Procedures, February. 2009.p.61.

JUNIOR, P.F.R; BARCELLOS, M.P.; TRIVILIN, L.O.; MARTINS, I.V.F.; SILVA, P.C.A.R.; Prevalência e controle das parasitoses gastrintestinais em bezerros de propriedades leiteiras no município de Alegre, Espirito Santo.Rev. Bras. Parasitol. Vet.v.15, n.4, p. 147-150, 2006.

KHUMPOOL, G.; Adaptation of the PERL-chamber system as an in vitro model for the percutaneous migration of infective larvae of Strongyloidespapillosus. Hannover, 2012.p.119.Tese (DoutoradoemMedicinaVeterinaria), University of Veterinary Medicine Hannover. Hannover, 2012.

KOBAYASHI, I.; HORII, Y.; Gastrointestinal motor disturbance in rabbits experimentally infected with Strongyloidespapillosus. Veterinary Parasitology.n.158. p.67-72. 2008.

LARSEN, M. Biological control of helminthes.InternationalJournal for Parasitology, v.29, p.139-146, 1999.

MONTEIRO, S.G.; Parasitologia veterinária. [Santa Maria: s.n.], 2007.p.274.

PEREIRA, R.H.M.A.; AHID, S.M.M.; BEZERRA, A.C.D.S.; SOARES, H.S.; FONSECA, Z.A.A.S.; Diagnóstico da resistência doa nematódóides gastrintestinais a anti-helmínticos em rebanhos caprino e ovino do RN. Acta VeterinariaBrasilia, v.2, n.1, p.16-19, 2008.

PINTO, J.M.S.; OLIVEIRA, M.A.L.; ALVARES, C.T.; COSTA-DIAS, R.; SANTOS, M.H.; Relação entre o periparto e a eliminação de ovos de Nematóides gastrintestinais em cabras anglo nubiana naturalmente infectadas em sistema semi-extensivo de produção.Ver. Bras. Parasitol. Vet., v.17, n. 1, p.138-143, 2008.

QUADROS, D.G.; RODRIGUES, L.R.A.; XAVIER, C.P.; SOUZA E CUNHA, M.L.C.; PEREIRA, D.C.S.;CUNHA NETO, W.C.; FEITOSA, J.V.; Prevalência de helmintos gastrintestinais em cabras e ovelhas pastejando capim-mombaça. In: REUNIÃO ANUAL DA SOCIEDADE BRASILEIRA DE ZOOTECNIA. 41., 2004, Campo Grande.Anais...Campo Grande: Universidade Estadual da Bahia, 2004.p.1-5. 
SANTOS, K.R.; FACIULLI, P.; PAPAROTTO, T.; TAKAHIRA, R.K.; LOPES, R.S.; SILVA, R.J.; FirstreportofStrondyloidessp. (Nematoda, Strongyloididae) in Leopardustigrinus(Carnivora: Felidae) in the municipality of Botucatu, State of São Paulo, Brazil. Rev. Bras. Parasitol. Vet., Jaboticabal, v.18, nl. 1, p. 77-79, dez. 2009.

SANTOS, T.R.; LOPES, W.D.Z.; BUZULINI, C.; BORGES, F.A.; SAKAMOTO, A.M.; LIMA, R.C.A.; OLIVEIRA, G.P.; COSTA, A.J.; Helminth fauna of bovines from the Central - Western region, Minas Gerais State, Brazil. Ciência Rural, Sante Maria, v.40, n.4, p.934-938, abr, 2010.

SILVA, A.R.; ARAUJO, J.V.; BRAGA, F.R.; OLIVEIRA, A.C.; CARVALHO, R.O.; ARAUJO, J.M.; CASTEJON, F.V.; Avaliação da eficácia de compostos anti-helmínticos sobre nematóides parasitos gastrintestinais (Strongyloidea) de caprinos. Rev. Bras. Parasitol. Vet., v.17, n. 1, p.120-125, 2008.

SILVA, A.R.; Eficácia de compostos anti-helmínticos sobre nematóides parasitos gastrintestinais (strongyloidea) de caprinos.Viçosa, 2008. p.91.Dissertação (Mestrado em Medicina Veterinária). Universidade Federal de Viçosa, 2008.

SOUTELLO, R.V.G. et al.The prevalence of anthelmintic resistance in nematode parasites of cattle in Sao Paulo state, Brazil. In: INTERNATIONAL CONFERENCE OF THE WORLD ASSOCIATION FOR THE ADVANCEMENT OF VETERINARY PARASITOLOGY, 19., 2003. New Orleans. Anais...New Orleans: Louisiana State University and WAAVP 2003 Local Organizing Committee, 2003. p.275.

STREIT, A.; Reproduction in Strongyloides (Nematoda): a life between sex and parthenogenesis.Parasitology. v.135. n.03. p. 285-294. março, 2008.

UENO, H.; GONÇALVES, P.C. Manual para diagnóstico das helmintoses de ruinantes. Tóquio: Jica, 1998. 166p. Disponível em:

$<$ http://www.google.com.br/url?sa =t\&rct=j\&q=\&esrc=s\&frm $=1 \&$ source $=$ web \&cd $=1 \& v e d=0 C D$

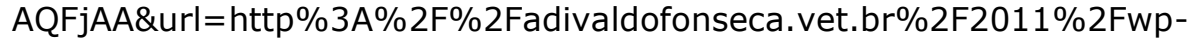

content $\% 2$ Fuploads\%2Fmanual_helmintoses $\% 2520$ UENO $\% 2520$ site $\% 2520$ do $\% 2520$ CBPV.pdf

\&ei=mA_7UO-

8JIai9QTz6YD4BA\&usg=AFQjCNEP1H3xPQbQgmQ0BK70ao0cDEu9wA\&sig2=TFCwYwB_4

f5TJWCWvMqtFQ\&bvm=bv.41248874, d.eWU>.

VIANA, R. B.; BISPO, J. P. B.; ARAUJO, C. V.; BENIGNO, R. N. M.; MONTEIRO, B. M.; GENNARI, S. M.; Dinâmica da eliminação de ovos por nematódeos gastrintestinais, durante o periparto de vacas de corte, no Estado do Pará. Ver. Bras. Parasitol. Vet., Jaboticabal, v.18, n.4, p. 49-52, out.-dez. 2009.

VIEIRA, F.M.; LIMA, S.S.; BESSA, E.C.A.; Morfologia e biometria de ovos e larvas de Strongyloidessp. grassi, 1879 (Rhabditoidea: Strongyloididae) Parasito gastrointestinal de Hydrochaerishydrochaeris (Linnaeus, 1766) (Rodentia: Hydrochaeridae), no município de Juiz de fora, Minas Gerais. Rev. Bras. Parasitol. Vet. v.15, n.1, p.7-12, 2006.

VIEIRA, L.S. Métodos alternativos de controle de nematóides gastrintestinais em caprinos e ovinos. Simposio Internacional sobre Caprinos e Ovinos de corte. 3., 2007, João Pessoa. Anais...João Pessoa: Universidade Federal daParaiba, 2007.p. 49-56. 